\title{
DEPENDENSI DALAM MODEL RESIKO INDIVIDUAL UNTUK ASURANSI JIWA KELOMPOK
}

\section{DEPENDENCE IN THE INDIVIDUAL RISK MODEL FOR GROUP LIFE INSURANCE}

\author{
Getut Pramesti ${ }^{1}$ dan Sri Haryatmi Kartiko ${ }^{2}$ \\ ${ }^{1}$ Program Studi Pendidikan Matematika, F PMIPA UNS, \\ ${ }^{2}$ Program Studi Matematika, F MIPA UGM
}

\begin{abstract}
ABSTRAK
Dependensi resiko dalam suatu portofolio asuransi untuk jenis asuransi jiwa kelompok dapat digambarkan sebagai model resiko individual. Dari model inilah dapat diketahui distribusi klaim dari suatu kontrak asuransi yang terjadi selama periode tertentu. Penghitungan distribusi dilakukan dengan menggunakan metode direct calculation melalui $n$ konvolusi distribusi klaim individual. Dibahas pula pengaruh dependensi resiko terhadap batas stop-loss premium dan dependensi resiko dengan tiga faktor resiko.

Kata-kata kunci : Dependensi resiko, asuransi jiwa kelompok, model resiko individual, klaim, batas stop-loss premium.
\end{abstract}

\section{ABSTRACT}

The risk dependence of an insurance portfolio in a group life insurance can be described as the individual risk model. It is used in modeling the claim distribution of insurance contracts over a fixed period of time. The distribution computation is conducted with direct calculation throught $n$ convolution of individual claim distribution. We discuss the impact of the risk dependence on the net value of the stop-loss premium. A third risk factor in the dependence risk model is also introduced. Key words : The risk dependence, group life insurance, individual risk model, claim, the net value of the stop-loss premium.

\section{PENDAHULUAN}

Perusahaan asuransi sebagai penanggung resiko dituntut untuk dapat menganalisa resiko yang meliputi identifikasi dan kalkulasi faktorfaktor yang mempengaruhinya. Perilaku resiko yang dihasilkan oleh $n$ polis digambarkan dengan distribusi klaim agregasi dalam suatu model resiko individual. Umumnya dalam model diasumsikan resikonya saling independen. Masalah yang kemudian muncul adalah apakah asumsi independensi resiko dalam model selalu sesuai dalam semua jenis asuransi. Dalam asuransi jiwa kelmpok misalnya, muncul masalah keterkaitan antar faktor resiko yang sangat mempengaruhi distribusi klaim dan batas stop-loss premiumnya.

Pada makalah ini dikaji dependensi dalam model resiko individual menggunakan metode direct calculation dan hubungannya dengan independensi resiko dalam asuransi jiwa kelompok serta pengaruhnya terhadap batas stop-loss premium.

\section{DASAR TEORI}

Dalam sistem asuransi ketidaktentuan yang melahirkan kerugian (loss) dari tertanggung (nasabah perusahaan asuransi) menimbulkan klaim yang diajukan dari tertanggung kepada penanggung (perusahaan asuransi). Namun sebelumnya tertanggung dikenakan biaya premi 
agar mendapat santunan dari penanggung. Adapun jumlahan klaim dalam suatu kontrak asuransi disebut dengan klaim agregasi dan digambarkan dalam suatu model resiko individual. Distribusi klaim agregasi dapat dihitung melalui n konvolusi klaim individual, yaitu dengan menggunakan lemma 2.1.

\section{Lemma 2.1}

Jika $X, Y$ variabel random independen dan $S=X+Y$ maka konvolusi dari pasangan fungsi distribusi $F_{X}$ dan $F_{Y}$ adalah $F_{S}(s)=F_{X} * F_{Y}(s) \quad$ dengan $F_{S}(s)=\sum_{y \leq s} F_{X}(s-y) d F_{Y}(y)$.

\section{Bukti :}

Diketahui $S=X+Y$ maka ruang sampel $S$ dapat ditunjukkan dalam Gambar 1.

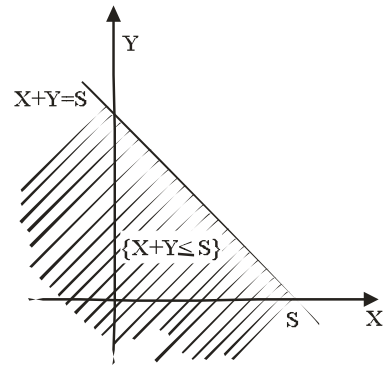

Gambar 1. Ruang sampel $S, S=X+Y$

Garis $X+Y=s$ dan daerah yang diarsir menyatakan kejadian $[S \leq X+Y \leq s]$, sedangkan fungsi distribusi kumulatif dari $S$ adalah :

Untuk $X$ dan $Y$ variabel random diskrit berlaku :

$$
\begin{aligned}
F_{S}(s) & =P(S \leq s) \\
& =\sum_{y \leq s} P(X+Y \leq s \mid Y=y) P(Y=y)
\end{aligned}
$$

$$
\begin{aligned}
& =\sum_{y \leq s} F_{X}(s-y) d F_{Y}(y) \\
& =F_{X} * F_{Y}(s)
\end{aligned}
$$

Untuk $X$ dan $Y$ variabel random kontinu, fungsi distribusi kumulatif $S$ adalah:

$$
\begin{aligned}
F_{S}(s) & =\int_{0}^{s} P(X+Y \leq s) P(Y=y) d y \\
& =\int_{0}^{s} F_{X}(s-y) f_{Y}(y) d y \\
& =F_{X} * F_{Y}(s)
\end{aligned}
$$

Jadi untuk $\mathrm{X}$ dan $\mathrm{Y}$ variabel random independen diperoleh konvolusi pasangan fungsi distribusi $F_{X}$ dan $F_{Y}$ adalah $F_{S}(s)=F_{X} * F_{Y}(s)$

Dalam asuransi dikenal istilah stop-loss asuransi yaitu pembayaran atau penggantian semua kerugian tertanggung apabila kerugian yang terjadi melebihi suatu batas moneter tertentu (disebut deductible) yang telah disepakati oleh pihak tertanggung dan penanggung (L. Xu dan D.L Bricker, 2000). Penetapan premi dari sistem asuransi ini disebut dengan stop-loss premium. Harga batas stop-loss premium dinotasikan dengan $E\left[(S-d)_{+}\right]$(Klugman et al, 1990) dengan $S$ adalah besar klaim agregasi dan $d$ adalah deductible $(d \geq 0)$ yaitu:

$$
E\left[(S-d)_{+}\right]= \begin{cases}\int_{d}^{\infty}\left[1-F_{S}(x)\right] d x, & x \text { kontinu. } \\ \sum_{x \geq d}\left[1-F_{S}(x)\right], & x \text { diskrit. }\end{cases}
$$




\section{DEPENDENSI DALAM MODEL RESIKO}

INDIVIDUAL UNTUK ASURANSI JIWA

KELOMPOK

\section{Konsep Dasar Model Resiko Individual}

Apabila dalam suatu periode asuransi yang berlaku selama 1 tahun penanggung akan membayar santunan sebesar $b$ jika tertanggung mengalami kerugian dalam periode tersebut dengan probabilitas terjadi $q$ maka variabel random klaim yang dinyatakan dengan $X$ dapat digambarkan baik dengan $f_{X}(x)$ maupun $F_{X}(x)$ yaitu:

$f_{X}(x)=P(X=x)= \begin{cases}1-q, & x=0 . \\ q, & x=b . \\ 0, & x \text { lain. }\end{cases}$

dan,

$F_{X}(x)=P(X \leq x)=\left\{\begin{aligned} 0, & x<0 \\ 1-q, & 0 \leq x<b . \\ 1, & x \geq b .\end{aligned}\right.$

dengan rata-rata dan variansinya adalah $E[X]=b q$ dan $\operatorname{Var}(X)=b^{2} q p$.

Apabila $I$ adalah variabel random Bernoulli atau variabel random Binomial untuk kejadian tunggal yang bernilai 1 jika terjadi klaim dan 0 jika tidak terjadi klaim maka $X$ dapat dinyatakan $X= \begin{cases}b, & I=1 . \\ 0, & I=0 .\end{cases}$

dengan $\quad P(I=0)=1-q, P(I=1)=q$ dan memiliki harga rata-rata serta variansi : $E[I]=q$ dan $\operatorname{Var}(I)=q p$.

Independensi dalam model resiko individual

Jika $X_{i}$ menyatakan klaim yang dihasilkan oleh polis ke- $i(i=1, \ldots, n)$, maka klaim agregasi $S$ yang merupakan jumlahan $X_{i}(i=1, \ldots, n)$ didefinisikan :

$$
S=\sum_{i=1}^{n} X_{i}
$$

dengan $X_{i}(i=1, \ldots, n)$ merupakan variabel random bernilai non negatif.

Apabila probabilitas variabel random Bernoulli $I_{i}(i=1, \ldots, n)$ :

$$
\begin{gathered}
P\left(I_{i}=1\right)=q_{i} \\
P\left(I_{i}=0\right)=1-q_{i}=p_{i}
\end{gathered}
$$

Maka $X_{i}(i=1, \ldots, n)$ dapat didefinisikan sebagai :

$$
X_{i}= \begin{cases}B_{i}, & I_{i}=1 . \\ 0, & I_{i}=0\end{cases}
$$

Jika $\quad X_{i}(i=1, \ldots, n) \quad$ diasumsikan saling independen maka distribusi dari klaim agregasi $S$ dapat ditentukan dengan metode direct calculation yaitu:

$$
\begin{aligned}
M_{X_{i}}(t) & =E_{I_{i}}\left\{E\left[e^{t X_{i}} \mid I_{i}\right]\right\} \\
& =\sum_{I_{i}} E\left[e^{t X_{i}} \mid I_{i}\right] P\left(I_{i}\right) \\
& =E\left[e^{t B_{i}}\right] q_{i}+p_{i} \\
M_{X_{i}}(t)=p_{i}+q_{i} & M_{B_{i}}(t)
\end{aligned}
$$

Dari hubungan :

$$
M_{X_{i}}(t)=P_{I_{i}}\left(M_{B_{i}}(t)\right)
$$

Diperoleh $M_{S}(t)$ yaitu sebagai berikut :

$$
M_{S}(t)=\prod_{i=1}^{n}\left\{p_{i}+q_{i} M_{B_{i}}(t)\right\}
$$

Dari (3.2.2), (3.2.3) dan (3.2.4) diketahui distribusi klaim $X_{i}(i=1,2, \ldots, n)$ yaitu

$$
F_{X_{i}}(x)=p_{i} \Delta_{0}(x)+q_{i} F_{B_{i}}(x)
$$


dengan $\Delta_{0}(x)= \begin{cases}1, & x \geq 0 . \\ 0, & x<0 .\end{cases}$

Sedangkan fungsi distribusi dan fungsi densitas probabilitas klaim agregasi $S$ :

$$
\begin{aligned}
& F_{S}(x)=F_{X_{1}} * F_{X_{2}} * \cdots * F_{X_{n}}(x) \\
& f_{S}(x)=f_{X_{1}} * f_{X_{2}} * \cdots * f_{X_{n}}(x)
\end{aligned}
$$

Untuk dua variabel random diskrit non negatif, misalkan $X_{1}$ dan $X_{2}$ dengan fungsi distribusi kumulatif $F_{X_{1}}$ dan $F_{X_{2}}$ dapat ditentukan distribusi kumulatif klaim agregasinya dengan menggunakan lemma 2.3.1 yaitu sebagai berikut :

$$
\begin{aligned}
F_{S}(s) & =\sum_{x_{2}} P\left(X_{1}+X_{2} \leq s \mid X_{2}=x_{2}\right) P\left(X_{2}=x_{2}\right) \\
& =F_{X_{1}} * F_{X_{2}}(s)
\end{aligned}
$$

Dari (3.2.2), (3.2.3) dan (3.2.4) diketahui bahwa :

$f_{X_{i}}(x)= \begin{cases}q_{i}, & x=b_{i} . \\ p_{i}=1-q_{i}, & x=0 .\end{cases}$

Dan $\quad S_{i}=S_{i-1}+X_{i}, \quad i=2, \ldots, n$

dengan nilai awal $S_{1}=X_{1}$. Sehingga diperoleh hasil

$$
f_{S_{i}}(x)=f_{S_{i-1}} * f_{X_{i}}(x)
$$

Dengan metode konvolusi persamaan (3.2.11) dapat ditentukan yaitu sebagai berikut :

$f_{S_{i}}(x)=\left\{\begin{array}{cc}p_{i} f_{S_{i-1}}(x), & x<b_{i} . \\ p_{i} f_{S_{i-1}}(x)+q_{i} f_{S_{i-1}}\left(x-b_{i}\right), & \left.x \geq b_{i} .12\right)\end{array}\right.$

Adapun rata-rata dan variansi dari klaim agregasi $S$ yaitu

$$
E[S]=\sum_{i=1}^{n} b_{i} q_{i}
$$

$\operatorname{Var}(S)=\sum_{i=1}^{n} b_{i}^{2} q_{i}\left(1-q_{i}\right)$

\section{Dependensi dalam Model Resiko Individual}

Dependensi resiko digambarkan melalui kejadian variabel random $I_{i}(i=1, \ldots, n)$ yang menyatakan terjadinya klaim pada polis ke-i. $I_{i}(i=1, \ldots, n)$ tergantung pada dua variabel random independen berdistribusi Bernoulli $J_{i i}(i=1, \ldots, n) \quad$ dan $\quad J_{0} . \quad J_{i i}(i=1, \ldots, n)$ menyatakan klaim terjadi karena faktor resiko individual (individual risk factor) ke- $i$ sedangkan $J_{0}$ menyatakan terjadinya klaim karena faktor resiko serentak (common risk factor). Probabilitas $J_{i i}(i=1, \ldots, n)$ dan $J_{0}$ adalah $P\left(J_{i i}=1\right)=q_{i i}, P\left(J_{i i}=0\right)=1-q_{i i}=p_{i i}$ dan $P\left(J_{0}=0\right)=1-q_{0}=p_{0} \quad P\left(J_{0}=1\right)=q_{0}$. Dari pengertian di atas, $I_{i}(i=1, \ldots, n)$ didefinisikan sebagai:

$I_{i}=\min \left(J_{i i}+J_{0}, 1\right)$

Dari definisi (3.3.1) vektor random $\left(I_{1}, I_{2}, \ldots, I_{n}\right)$ merupakan komponen yang saling dependen, hal ini berakibat $\left(X_{1}, X_{2}, \ldots, X_{n}\right)$ juga saling dependen.

Parameter $q_{i}$ pada persamaan (3.2.2) dapat dinyatakan sebagai fungsi $q_{i i}$ dan $q_{0}$, hal ini dapat ditunjukkan sebagai berikut :

$$
\begin{aligned}
P_{I_{i}}(t) & =E_{j_{0}}\left\{E\left[t^{I_{i}} \mid J_{0}\right]\right\} \\
& =p_{0}\left(p_{i i}+q_{i i} t\right)+t q_{0}
\end{aligned}
$$

Sehingga

$P_{I_{i}}(t)=p_{0} p_{i i}+\left(1-p_{0} p_{i i}\right) t$.

Jadi diperoleh hubungan

$$
p_{i}=p_{0} p_{i i} .
$$




$$
\left.\left.q_{i}=1-\left(1-q_{0}\right)\left(1-q_{i i}\right) .\right) \quad\right)
$$

Dari (3.3.3) dan (3.3.4) dapat diketahui jika $q_{0}=0$ maka diperoleh model resiko individual dengan resiko independen dimana $q_{i}=q_{i i}$.

Bila fungsi pembangkit momen $\left(X_{1}, X_{2}, \ldots, X_{n}\right)$ adalah $M_{X_{1}, \ldots, X_{n}}\left(t_{1}, \ldots, t_{n}\right)=E\left[e^{t_{1} x_{1}+\cdots+t_{n} x_{n}}\right]$ dan fungsi pembangkit probabilitas $\left(I_{1}, I_{2}, \ldots, I_{n}\right)$ adalah $P_{I_{1}, \ldots, I_{n}}\left(t_{1}, \ldots, t_{n}\right)=p_{0} \prod_{i=1}^{n} E\left[t_{i}^{J_{i i}}\right]+q_{0} \prod_{i=1}^{n} t_{i}$

maka :

$$
\begin{aligned}
& M_{X_{1}, X_{2}, \ldots, X_{n}}\left(t_{1}, \ldots, t_{n}\right)= \\
& p_{0} \prod_{i=1}^{n} P_{J_{i i}}\left(M_{B_{i}}\left(t_{i}\right)\right)+q_{0} \prod_{i=1}^{n} M_{B_{i}}\left(t_{i}\right) .
\end{aligned}
$$

Selanjutnya, dengan menggunakan lemma 3.3.1.

\section{Lemma 3.3.1}

Apabila $M_{Y_{1}, \ldots, Y_{n}}\left(t_{1}, \ldots, t_{n}\right)$ adalah fungsi pembangkit momen multivariat dari vektor $\left(Y_{1}, \ldots, Y_{n}\right)$ maka fungsi pembangkit momen dari $Z=Y_{1}+Y_{2}+\cdots+Y_{n} \quad$ adalah $M_{Z}(t)=M_{Y_{1}, \ldots, Y_{n}}(t, \cdots, t)$

dapat diperoleh fungsi pembangkit momen dari $S$ yaitu :

$M_{S}(t)=p_{0} \prod_{i=1}^{n} P_{J_{i i}}\left(M_{B_{i}}(t)\right)+q_{0} \prod_{i=1}^{n} M_{B_{i}}(t)$.

Jika dimisalkan $V$ dan $U$ adalah variabel random dengan fungsi pembangkit momen:

$$
\begin{aligned}
& M_{V}(t)=\prod_{i=1}^{n} P_{J_{i i}}\left(M_{B_{i}}(t)\right), \\
& M_{U}(t)=\prod_{i=1}^{n} M_{B_{i}}(t) .
\end{aligned}
$$

Diperoleh distribusi klaim agregasi $S$ :

$$
F_{S}(x)=p_{0} F_{V}(x)+q_{0}(x) F_{U}(x), \quad x \geq 0
$$

Bentuk (3.3.10) dapat dinyatakan sebagai:

$$
\begin{aligned}
F_{S}(x)= & \left(1-q_{0}\right)\left(F_{D_{1}} * \cdots * F_{D_{n}}(x)\right) \\
& +q_{0}\left(F_{B_{1}} * \cdots * F_{B_{n}}(x)\right), \quad x \geq 0
\end{aligned}
$$

Dengan

$F_{D_{i}}(x)=p_{i i} \Delta_{0}(x)+q_{i i} F_{B_{i}}(x)$,

$(i=1,2, \ldots, n)$.

Fungsi distribusi $F_{V}$ dan $F_{U}$ pada (3.3.10) ditentukan menggunakan Lemma 2.3.1, persamaan (3.2.12) dan (3.2.13). Selanjutnya dari bentuk (3.3.10) distribusi kumulatif klaim agregasi dibentuk dari kombinasi antara distribusi kumulatif resiko individual dan resiko serentak.

Adapun harga rata-rata dan variansi dari klaim agregasi $S$ adalah :

$$
E[S]=\sum_{i=1}^{n} E\left[X_{i}\right]
$$

$$
\begin{aligned}
& \operatorname{Var}(S)=\sum_{i=1}^{n} \operatorname{Var}\left(X_{i}\right)+ \\
& 2 \frac{q_{0}}{1-q_{0}} \sum_{i=1}^{n-1} \sum_{k=i+1}^{n} E\left[B_{i}\right] E\left[B_{k}\right]\left(1-q_{i}\right)\left(1-q_{k}\right)
\end{aligned}
$$

Dari (3.3.13), apabila kemungkinan terjadinya klaim karena faktor resiko serentak (common risk factor) membesar maka variansi klaim agregasi semakin besar.

\section{Stop-loss Premium}

Dari definisi (2.3.4.1),(2.3.4.2) dan persamaan (3.3.10) dapat diperoleh harga batas stop-loss premium dengan dua faktor dependensi resiko adalah 


$$
E\left[(S-d)_{+}\right]=\left\{\begin{array}{l}
\int_{d}^{\infty}\left[1-\left\{\left(1-q_{0}\right) F_{V}(x)+q_{0} F_{U}(x)\right\}\right] d x, x \text { kontinu } \\
\sum_{x \geq d}\left[1-\left\{\left(1-q_{0}\right) F_{V}(x)+q_{0} F_{U}(x)\right\}\right], x \text { diskrit }
\end{array}\right.
$$

dengan $d$ (deductible) $\geq 0$.

Dari (3.4.1) dan (3.4.2) nampak bahwa jika nilai $q_{0}$ semakin besar, yang juga mengakibatkan semakin kecilnya nilai $p_{0}$ maka batas stop-loss premiumnya akan semakin besar. Selain itu untuk $q_{0}=0$ diperoleh harga batas stop-loss premium untuk model resiko individual dengan resiko saling independen. Beberapa sifat yang berkaitan dengan batas stop-loss premium dijelaskan Teorema 3.4.1 dan 3.4.2.

Teorema 3.4.1

Jika $P(a<S<b)=0$ maka untuk suatu $a \leq d \leq b$ berlaku :

$$
\begin{aligned}
E\left[(S-d)_{+}\right]= & \frac{b-d}{b-a} E\left[(S-a)_{+}\right] \\
& +\frac{d-a}{b-a} E\left[(S-b)_{+}\right] .
\end{aligned}
$$

\section{Teorema 3.4.2}

Jika $\quad P(S=k h)=f_{k} \geq 0, \quad h>0, k=0,1, \ldots$ dan $P(S=x)=0$ untuksetiap $x$ maka untuk suatu $d=j h$ berlaku :

$$
\left.E\left[(S-d)_{+}\right]=h \sum_{m=0}^{\infty}\left\{1-F_{S}[(m+j) h]\right\} .\right)
$$

\section{Dependensi Resiko dalam m kelas Portofolio}

\section{Asuransi}

Apabila portofolio asuransi terbagi dalam $m$ kategori kelas dengan $j=1, \ldots, m$, setiap kelas $j$ terdiri dari $n_{j}$ resiko, $X_{j k}$ menyatakan klaim dalam polis ke- $k$ dalam kelas $j$ dengan $k=1,2, \ldots, n_{j}$ dan $S$ dinyatakan dengan :

$$
S=\sum_{j=1}^{m} \sum_{k=1}^{n_{j}} X_{j k}
$$

Terjadinya klaim tiga dependensi faktor resiko digambarkan oleh variabel random $I_{j k}\left(j=1, \ldots, m ; k=1,2, \ldots, n_{j}\right) \quad$ menyatakan terjadinya klaim kelas $j$, polis ke- $k$. Apabila $I_{j k}\left(j=1, \ldots, m ; k=1,2, \ldots, n_{j}\right)$ variabel random Bernoulli maka $I_{j k}\left(j=1, \ldots, m ; k=1,2, \ldots, n_{j}\right)$ dinyatakan sebagai fungsi 3 faktor resiko saling independen yaitu $J_{j k}\left(j=1, \ldots, m ; k=1, \ldots, n_{j}\right)$, faktor resiko kelas $J_{j}(j=1, \ldots, m)$ dan faktor resiko serentak $J_{0} \quad$ dengan $I_{j k}\left(j=1, \ldots, m ; k=1,2, \ldots, n_{j}\right):$

$P\left(I_{j k}=1\right)=q_{j k}$,

$P\left(I_{j k}=0\right)=p_{j k}=1-q_{j k}$.

Dari deskripsi di atas $I_{j k}\left(j=1, \ldots, m ; k=1,2, \ldots, n_{j}\right)$ dapat

didefinisikan :

$$
I_{j k}=\min \left(J_{j k}+J_{j}+J_{0}, 1\right) \text {. }
$$

dimana $J_{j k}, J_{j}, J_{0}$ adalah variabel random berdistribusi Bernoulli dengan probabilitas: 
$P\left(J_{j k}=1\right)=q_{j k}^{*}, P\left(J_{j k}=0\right)=p_{j k}^{*}=1-q_{j k}^{*}$,

$P\left(J_{j}=1\right)=q_{j}^{*}, P\left(J_{j}=0\right)=p_{j}^{*}=1-q_{j}^{*}$,

Jadi

$P\left(J_{0}=1\right)=q_{0}^{*}, \quad P\left(J_{0}=0\right)=p_{0}^{*}=1-q_{0}^{*}$.

$M_{X_{j k}}(t)=p_{0}^{*} p_{j}^{*} p_{j k}^{*}+\left\{1-p_{0}^{*} p_{j}^{*} p_{j k}^{*}\right\} M_{B_{j k}}(t)$.

Variabel random $X_{j k}$ dalam (3.5.1) dapat

dinyatakan:

$$
X_{j k}=\left\{\begin{array}{c}
B_{j k}, I_{j k}=1 . \\
0, I_{j k}=0 .
\end{array}\right.
$$

Jika $B_{j k}$ merupakan variabel random yang menyatakan besar klaim jika polis ke- $k$

$$
\left(k=1,2, \ldots, n_{j}\right) \text { dalam kelas-j }(j=1, \ldots, m)
$$

terjadi klaim dan fungsi distribusi kumulatif dari $B_{j k}$ adalah $F_{B_{j k}}$ maka fungsi pembangkit probabilitas dari $I_{j k}\left(j=1, \ldots, m ; k=1,2, \ldots, n_{j}\right)$ adalah sebagai berikut :

$P_{I_{j k}}(t)=p_{j k}^{*} p_{j}^{*} p_{0}^{*}+\left(q_{j}^{*} p_{0}^{*}+q_{j k}^{*} p_{j}^{*} p_{0}^{*}+q_{0}^{*}\right) t$.

Dapat diketahui pula bahwa :

$$
\begin{aligned}
& p_{j k}=p_{j k}^{*} p_{j}^{*} p_{0}^{*}, \\
& q_{j k}=1-\left(1-q_{0}^{*}\right)\left(1-q_{j k}^{*}\right)\left(1-q_{j}^{*}\right)
\end{aligned}
$$

Dengan menggunakan (3.5.7) dan (3.5.8) diperoleh fungsi pembangkit momen dari $X_{j k}$ adalah sebagai berikut:

$$
\begin{aligned}
M_{X_{j k}}(t)= & E_{I_{j k}}\left\{E\left[e^{t X_{j k}} \mid I_{j k}\right]\right\}=\quad \text { persamaan 3.5.12 dan 3.5.13. } \\
M_{B_{j k}}(t)\left\{1-\left(1-q_{0}^{*}\right)\left(1-q_{j}^{*}\right)\left(1-q_{j k}^{*}\right)\right\}+p_{j k}^{*} p_{j}^{*} p_{0}^{*} & \\
E[S]= & \sum_{j=1}^{m} \sum_{k=1}^{n_{j}} E\left[X_{j k}\right] \\
\operatorname{Var}(S)= & \sum_{j=1}^{m} \sum_{k=1}^{n_{j}} \operatorname{Var}\left[X_{j k}\right] \\
& +\sum_{j=1}^{m} \sum_{k=1}^{n_{j}} \sum_{k^{\prime}=1, k \neq k^{\prime}}^{n_{j}} E\left[B_{j k}\right] E\left[B_{j k^{\prime}}\right]\left(q_{0}^{*}+p_{0}^{*} q_{j}^{*}+p_{0}^{*} p_{j}^{*} q_{j k}^{*} q_{j k^{\prime}}^{*}-q_{j k}^{*} q_{j k^{\prime}}^{*}\right) \\
& +\sum_{j=1}^{m} \sum_{j^{\prime}=1, j^{\prime} \neq j}^{m} \sum_{k=1}^{n_{j}} \sum_{k^{\prime}=1}^{n_{j^{\prime}}} E\left[B_{j k}\right] E\left[B_{j^{\prime} k^{\prime}}\right]\left(q_{0}^{*}+p_{0}^{*}\left(q_{j}^{*}+p_{j}^{*} q_{j k}^{*}\right)\left(q_{j^{\prime}}^{*}+p_{j^{\prime}}^{*} q_{j^{\prime} k^{\prime}}^{*}\right)-q_{j k}^{*} q_{j^{\prime} k^{\prime}}^{*}\right)
\end{aligned}
$$




\section{Contoh Aplikasi}

Suatu kontrak asuransi jiwa kelompok berlaku dengan jangka waktu 1 tahun untuk 3 orang pekerja. Misalkan variabel tejadinya klaim $I_{1}, I_{2}, I_{3}$ berdistribusi Bernoulli dengan probabilitas $\quad q_{i}=0.05(i=1,2,3), \quad$ sedangkan variabel random besar klaim $B_{1}, B_{2}, B_{3}$ berdistribusi Cauchy dengan $\theta=1$ dan $\eta=0$. Diketahui probabilitas pekerja pertama, kedua dan ketiga akan mendapat santunan masingmasing 1, 2 dan 3 unit (unit dalam satuan Rp. $\left.10^{7},-\right)$ adalah $0.159155,0.063662,0.031831$ dan data seperti Tabel 1.

Tabel 1. Data ( $x$ dalam satuan Rp. $10^{7}$, ,)

\begin{tabular}{|c|c|c|c|}
\hline Klaim $(\boldsymbol{x})$ & $f_{1}(x)$ & $f_{2}(x)$ & $f_{3}(x)$ \\
\hline $\mathbf{0}$ & $\mathbf{0 . 3 1 8 3 1}$ & $\mathbf{0 . 3 1 8 3 1}$ & $\mathbf{0 . 3 1 8 3 1}$ \\
\hline $\mathbf{1}$ & $\mathbf{0 . 1 5 9 1 5 5}$ & $\mathbf{0 . 1 5 9 1 5 5}$ & $\mathbf{0 . 1 5 9 1 5 5}$ \\
\hline $\mathbf{2}$ & $\mathbf{0 . 0 6 3 6 6 2}$ & $\mathbf{0 . 0 6 3 6 6 2}$ & $\mathbf{0 . 0 6 3 6 6 2}$ \\
\hline $\mathbf{3}$ & $\mathbf{0 . 0 3 1 8 3 1}$ & $\mathbf{0 . 0 3 1 8 3 1}$ & $\mathbf{0 . 0 3 1 8 3 1}$ \\
\hline $\mathbf{4}$ & & $\mathbf{0 . 0 1 8 7 2 4}$ & $\mathbf{0 . 0 1 8 7 2 4}$ \\
\hline $\mathbf{5}$ & & & $\mathbf{0 . 0 1 2 2 4 3}$ \\
\hline
\end{tabular}

Dipilih tiga alternatif probabilitas terjadinya klaim karena faktor resiko serentak $q_{0}$ adalah $0.00625,0.003125$ dan 0 , aktuaris perusahaan asuransi tersebut ingin memprediksi distribusi kumulatif klaim agregasi dan harga minimum premi selama jangka waktu 1 tahun tersebut.

Nilai distribusi kumulatif klaim agregasi dan harga batas stop-loss premium untuk nilai klaim $x=0,1, \ldots, 12$ ( $x$ dalam satuan $\left.\operatorname{Rp} 10^{7},-\right)$ dapat dilihat pada Tabel 2.
Dari Tabel 2, distribusi klaim agregasi semakin besar apabila nilai $q_{0}$ semakin kecil, jadi klaim terbesar kemungkinan muncul karena faktor resiko individunya. Sedangkan batas stop-loss premium akan semakin kecil apabila nilai $q_{0}$ semakin kecil. Hal ini mengakibatkan harga premi dari asuransi jiwa kelompok akan lebih mahal dibanding dengan asuransi jiwa perseorangan.

Adapun plot dari distribusi kumulatif klaim agregasi dan harga batas stop-loss premium dapat di lihat pada Plot 1 dan 2.

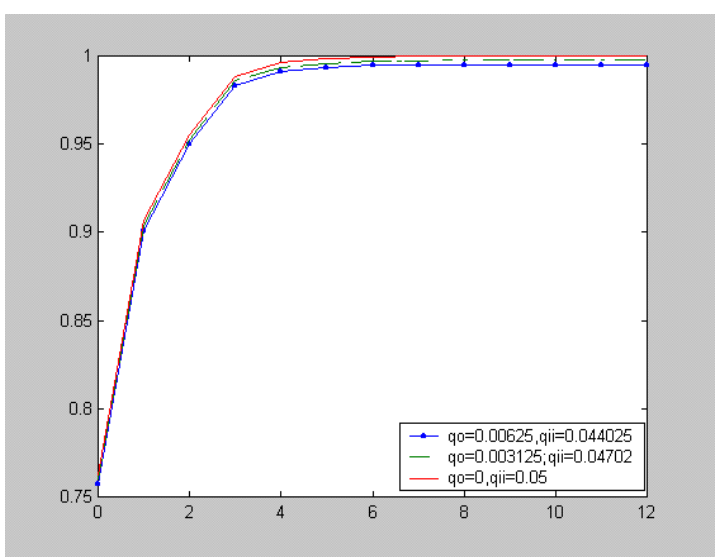

Plot 1. Fungsi distribusi kumulatif klaim agregasi

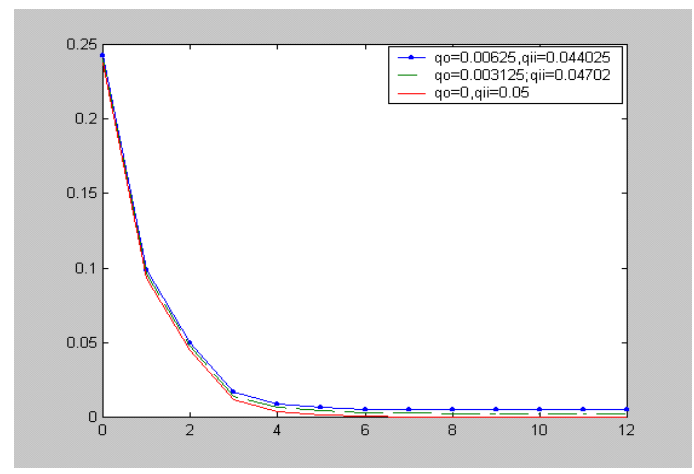

Plot 2. Batas stop-loss premium

Dari plot 1 dan 2 nampak bahwa distribusi kumulatif klaim agregasi dan harga batas stoploss premium dengan dua faktor resiko saling dependen dipengaruhi oleh faktor resiko serentak dan faktor resiko individual. 
Tabel 2. Distribusi klaim

\begin{tabular}{|c|c|c|c|c|c|c|}
\hline & $q_{0}=\mathbf{0 . 0 0 6 2 5}$ & $q_{0}=\mathbf{0 . 0 0 3 1 2 5}$ & $q_{0}=\mathbf{0}$ & $q_{0}=\mathbf{0 . 0 0 6 2 5}$ & $q_{0}=\mathbf{0 . 0 0 3 1 2 5}$ & $q_{0}=\mathbf{0}$ \\
$\boldsymbol{x}$ & $F_{S_{1}}(x)$ & $F_{S_{2}}(x)$ & $F_{S_{3}}(x)$ & $S L_{1}$ & $S L_{2}$ & $S L_{3}$ \\
\hline $\mathbf{0}$ & $\mathbf{0 . 7 5 7 6 9 1}$ & $\mathbf{0 . 7 5 9 9 7 3}$ & $\mathbf{0 . 7 6 2 2 5 4}$ & $\mathbf{0 . 2 4 2 3 0 9}$ & $\mathbf{0 . 2 4 0 0 2 7}$ & $\mathbf{0 . 2 3 7 7 4 6}$ \\
\hline $\mathbf{1}$ & $\mathbf{0 . 9 0 1 3 7 1}$ & $\mathbf{0 . 9 0 3 9 5 2}$ & $\mathbf{0 . 9 0 6 5 3 3}$ & $\mathbf{0 . 0 9 8 6 2 9}$ & $\mathbf{0 . 0 9 6 0 4 8}$ & $\mathbf{0 . 0 9 3 4 6 7}$ \\
\hline $\mathbf{2}$ & $\mathbf{0 . 9 4 9 8 6 7}$ & $\mathbf{0 . 9 5 2 4 6 3}$ & $\mathbf{0 . 9 5 5 0 6}$ & $\mathbf{0 . 0 5 0 1 3 3}$ & $\mathbf{0 . 0 4 7 5 3 7}$ & $\mathbf{0 . 0 4 4 9 4}$ \\
\hline $\mathbf{3}$ & $\mathbf{0 . 9 8 3 3 1 2}$ & $\mathbf{0 . 9 8 5 9 1}$ & $\mathbf{0 . 9 8 8 5 0 8}$ & $\mathbf{0 . 0 1 6 6 8 8}$ & $\mathbf{0 . 0 1 4 0 9}$ & $\mathbf{0 . 0 1 1 4 9 2}$ \\
\hline $\mathbf{4}$ & $\mathbf{0 . 9 9 1 0 8 5}$ & $\mathbf{0 . 9 9 3 6 3 8}$ & $\mathbf{0 . 9 9 6 1 9}$ & $\mathbf{0 . 0 0 8 9 1 5}$ & $\mathbf{0 . 0 0 6 3 6 2}$ & $\mathbf{0 . 0 0 3 8 1}$ \\
\hline $\mathbf{5}$ & $\mathbf{0 . 9 9 3 2 8 5}$ & $\mathbf{0 . 9 9 5 8 0 2}$ & $\mathbf{0 . 9 9 8 3 2}$ & $\mathbf{0 . 0 0 6 7 1 5}$ & $\mathbf{0 . 0 0 4 1 9 8}$ & $\mathbf{0 . 0 0 1 6 8}$ \\
\hline $\mathbf{6}$ & $\mathbf{0 . 9 9 4 5 8 1}$ & $\mathbf{0 . 9 9 7 0 8 1}$ & $\mathbf{0 . 9 9 9 5 8 1}$ & $\mathbf{0 . 0 0 5 4 1 9}$ & $\mathbf{0 . 0 0 2 9 1 9}$ & $\mathbf{0 . 0 0 0 4 1 9}$ \\
\hline 7 & $\mathbf{0 . 9 9 4 8 8 1}$ & $\mathbf{0 . 9 9 7 3 7 2}$ & $\mathbf{0 . 9 9 9 8 6 3}$ & $\mathbf{0 . 0 0 5 1 1 9}$ & $\mathbf{0 . 0 0 2 6 2 8}$ & $\mathbf{0 . 0 0 0 1 3 7}$ \\
\hline $\mathbf{8}$ & $\mathbf{0 . 9 9 4 9 6 9}$ & $\mathbf{0 . 9 9 7 4 5 6}$ & $\mathbf{0 . 9 9 9 9 4 3}$ & $\mathbf{0 . 0 0 5 0 3 1}$ & $\mathbf{0 . 0 0 2 5 4 4}$ & $\mathbf{5 . 7 E - 0 5}$ \\
\hline $\mathbf{9}$ & $\mathbf{0 . 9 9 5 0 1 4}$ & $\mathbf{0 . 9 9 7 5}$ & $\mathbf{0 . 9 9 9 9 8 6}$ & $\mathbf{0 . 0 0 4 9 8 6}$ & $\mathbf{0 . 0 0 2 5}$ & $\mathbf{1 . 4 E}-05$ \\
\hline 10 & $\mathbf{0 . 9 9 5 0 2 4}$ & $\mathbf{0 . 9 9 7 5 1}$ & $\mathbf{0 . 9 9 9 9 9 5}$ & $\mathbf{0 . 0 0 4 9 7 6}$ & $\mathbf{0 . 0 0 2 4 9}$ & $\mathbf{5 E}-06$ \\
\hline 11 & $\mathbf{0 . 9 9 5 0 2 8}$ & $\mathbf{0 . 9 9 7 5 1 3}$ & $\mathbf{0 . 9 9 9 9 9 8}$ & $\mathbf{0 . 0 0 4 9 7 2}$ & $\mathbf{0 . 0 0 2 4 8 7}$ & $\mathbf{2 E}-\mathbf{0 6}$ \\
\hline 12 & $\mathbf{0 . 9 9 5 0 3}$ & $\mathbf{0 . 9 9 7 5 1 5}$ & $\mathbf{1}$ & $\mathbf{0 . 0 0 4 9 7}$ & $\mathbf{0 . 0 0 2 4 8 5}$ & $\mathbf{0}$ \\
\hline
\end{tabular}

\section{KESIMPULAN DAN SARAN}

\section{Kesimpulan}

Dari pembahasan pada bab-bab sebelumnya, dapat diambil beberapa kesimpulan yaitu sebagai berikut :

1. Model resiko individual dengan dependensi dua faktor resiko : $F_{S}(x)=p_{0} F_{V}(x)+q_{0} F_{U}(x), \quad x \geq 0 . \quad$ Dari model tersebut dapat diketahui bahwa distribusi klaim agregasi tergantung dari distribusi klaim karena faktor resiko individual dan distribusi klaim karena faktor resiko serentak

2. Harga batas batas stop-loss premium sebagai berikut :

$$
E\left[(S-d)_{+}\right]=\left\{\begin{array}{l}
\int_{d}^{\infty}\left[1-\left(p_{0} F_{V}(x)+q_{0} F_{U}(x)\right)\right] d x \\
\sum_{x \geq \mathrm{d}}\left[1-\left(\mathrm{p}_{0} F_{V}(x)+q_{0} F_{U}(x)\right)\right]
\end{array}\right.
$$

Jadi harga batas stop-loss premium dengan dua faktor resiko yang saling dependen dipengaruhi oleh faktor resiko individual dan faktor resiko serentak.

\section{Saran}

Penulisan tesis ini dapat dikembangkan lebih lanjut dengan menggunakan metode fast fourier transform (FFT) atau metode lain untuk kasus jumlah klaim $n$ yang besar.

\section{DAFTAR PUSTAKA}

Bain, L. J., and Engelhard, M. (1992). Introduction to Probability and Mathematical Statistics. 2n ed. California : Duxbury Press.

Bauerle, N., and Muller. A. (1998). Modelling and comparing dependencies in 
multivariate risk portofolios. ASTIN Bulletin 28, 59-76.

Bowers, N., Gerber, H., Hickman, J., Jones, D., and Nesbitt, C. (1997). Actuarial Mathematics. Schaumburg, IL: Society of Actuaries.

Casella, G and Berger, R. L. (1990). Statistical Inference. California : Wadsworth.

De Pril, N. (1986). On the exact computation of the aggregate claims distribution in the individual life model. ASTIN Bulletin $16,109-112$.

Denuit, M., Genest, C., and Marceau, E. (1999). Stochastic bounds on dependent risks. Insurance : Mathematics and Economics, to appear.

Dhaene, J., and Goovaerts, M. J. (1996). Dependency of risks and stop-loss order. ASTIN Bulletin 26, 201-212.

Djojosoedarso, S. (1999). Prinsip-prinsip Manajemen risiko dan Asuransi. Cetakan pertama. Jakarta : Salemba Empat.

Giordano, R., F., and Weir, D., M. (1991). Differential equation a modeling approach. Addison Wesley, Canada.

Klugman, S. A., Panjer, H. H., Willmot, G., E. (1990). Loss Models : from data to decisions. New York : John Wiley and Sons.

L. Xu, D.L. Bricker. (2000). Bound for stoploss premium under restrictions on the Chi-Square Statistic. Insurance: Mathematics and Economics.
Morton, R., G. (1995). Dasar-Dasar Asuransi Jiwa dan Asuransi Kesehatan. Jakarta : Yayasan Dharma Bumiputera- AJB Bumiputera 1912.

Rolski, T., Schmidli, H., Scmidt, V., and Teugels, J. (1999). Stochastic Processes for Insurance and Finance. New York : John Wiley and Sons.

Waldmann, K. H. (1994). On the exact calculation of the aggregate claims distribution in the individual life model. ASTIN Bulletin 24, 89-96. 